\title{
Using a focused ion beam to characterize the microstructure of porous lanthanum strontium manganite (LSM) electrodes
}

\author{
A. Chen, J.R.Smith, R. T. DeHoff, and K.S. Jones \\ Department of Materials Science and Engineering, University of Florida, Gainesville, FL 32611
}

The relationship between the microstructure and electrochemical performance of lanthanum strontium manganite (LSM) /yttria stabilized zirconia (YSZ) solid oxide fuel cells (SOFC) was studied with respect to the isochronal sintering at temperatures between $950^{\circ} \mathrm{C}$ and $1400^{\circ} \mathrm{C}$ for times between 1 hour and 6 hours. Previous studies have shown that the performance of this materials system varies tremendously with materials properties and microstructure $[1,2]$ However, it is not clear how cathode polarization, the major component of the SOFC performance, depends on the different aspects of the microstructure. This study was focused on how two aspects of the microstructure: 1) triple-phase boundary (TPB) length, which represents number density of sites for the charge transfer reaction at the LSM/YSZ interface, and 2) pore area, which determines the area exposed for dissociative adsorption of oxygen, affects the cathode activation polarization. A technique using a dual-beam focused ion beam (FIB) system was developed to automatically slice serial sections of the electrode parallel to the surface and perpendicular to the surface with a narrow (760A) thickness per slice as shown in FIG 1. Software was used to reconstruct the 3-D pore structure from SEM images of each slice as shown in FIG 2. The homogeneity of the sample was studied by dissector analysis [3] to ensure an unbiased quantification of the cathode microstructure. The line intercept count $[4,5]$ was used to calculate TPB length per area and pore surface area per volume based on two dimensional sections. Porosity was quantified based on two dimensional images and 3-D pore structure, respectively. The electrochemical property of the sintered LSM cathodes was characterized by electrochemical impedance spectroscopy (EIS) measured in air at various temperatures ranging from $250{ }^{\circ} \mathrm{C}$ to $900{ }^{\circ} \mathrm{C}$.

It was found that TPB length was reduced from $1.41 \pm 0.07 \mathrm{um} / \mathrm{um}^{2}$ to $0.21 \pm 0.01 \mathrm{um} / \mathrm{um}^{2}$ as the 1 hour sintering temperature increased from $950^{\circ} \mathrm{C}$ to $1400^{\circ} \mathrm{C}$, and pore surface area at $1400{ }^{\circ} \mathrm{C}$ was eight times smaller than that at $950{ }^{\circ} \mathrm{C}$. In addition, cathode activation polarization was reduced with the increasing pore surface area as shown in FIG 3. This study shows that both microstructure evolution and the corresponding changes in cathode polarization changed dramatically above $1200^{\circ} \mathrm{C}$. The effect of isothermal sintering at $1200^{\circ} \mathrm{C}$ on both the cathode microstructure and cathode polarization will be presented.

\section{References}

[1] H. H. Mobius, J. Solid State Electrochem. 1 (1997) 2.

[2] M. J. Jorgensen et al., J. Appl. Electrochem. 30 (2000) 411.

[3] J.C. Russ, R.T. DeHoff, Practical Stereology, 2nd Edition, Plenum Press, New York, 2000

[4] S.A.Saltykov, Stereometric Metallography, Metallurgizdat,Moscow (1958)

[5] C.S.Smith, and L.Guttman:Measurement of Internal Boundaries in Three-Dimensional Structures by Random Sectioning, Trans.AIME, 197 (1953) 81

[5] The aid of Jerry Bourne, MAIC at University of Florida is gratefully acknowledged. 

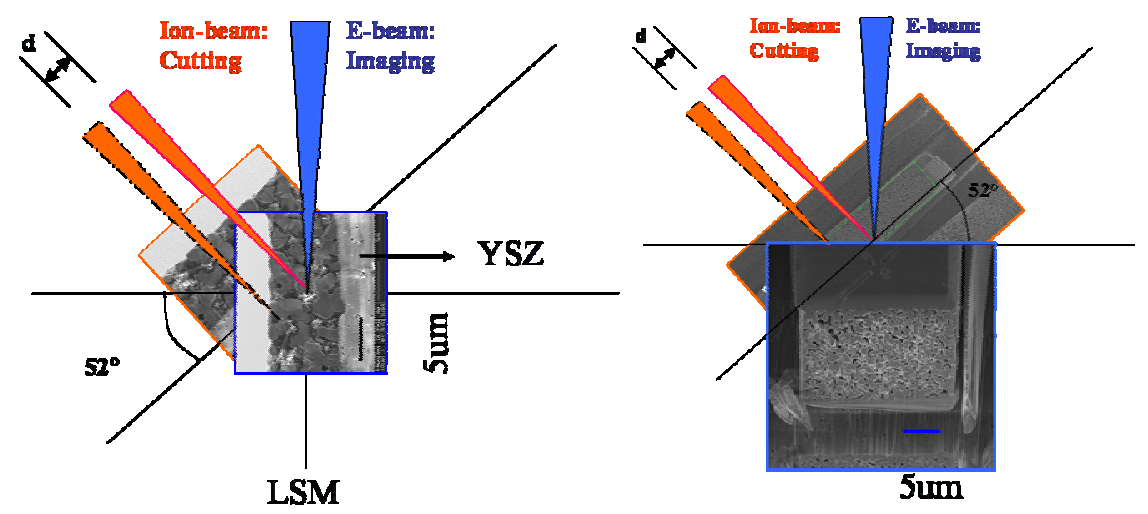

FIG 1 Basic principle of two dimensional serial sections for plane view and cross-section view by Focused ion beam

The spacing between two continuous cuts by primary ion beam is about $76 \mathrm{~nm}$.

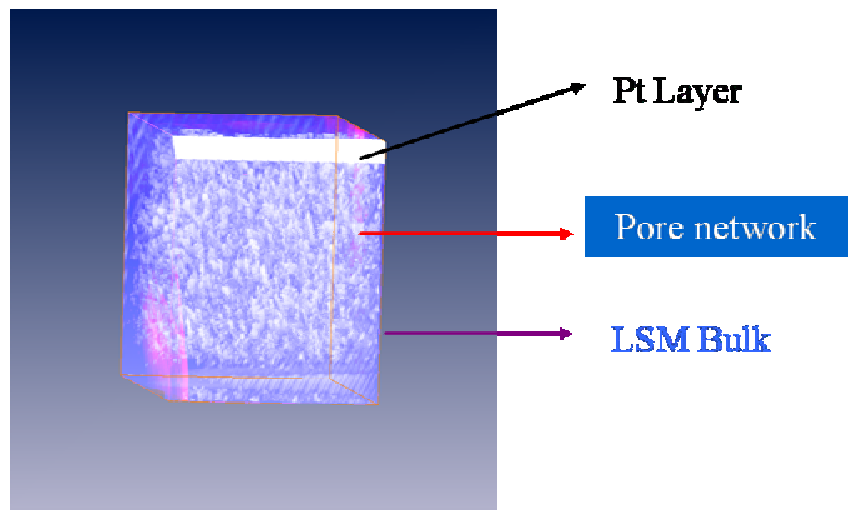

FIG 2 3D reconstruction of porous cathode with a volume of $18 \mathrm{um} * 9 \mathrm{um} * 30 \mathrm{um}$ The pore network floats in the bulk LSM, which shows as a bounding box.

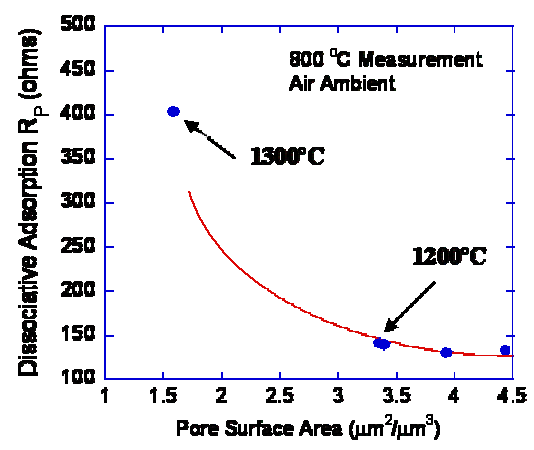

FIG 3 The effect of pore surface area on cathode polarization

Dissociative adsorption resistance depends on pore surface area. The change in cathode polarization was apparent starting at $1200^{\circ} \mathrm{C}$. 